\title{
Application of two models to the lactation curve of Massese ewes
}

\author{
O. Franci*, C. Pugliese, A. Acciaioli, G. Parisi, M. Lucifero \\ Dipartimento di Scienze Zootecniche dell, Università di Firenze, via delle Cascine 5, 50144 Firenze, Italy
}

Accepted 15 April 1998

\begin{abstract}
The experiment was carried out on 52 lactations of 37 multiparous Massese ewes. Milk yield was recorded weekly, starting before the 15th day from lambing. Due to the mating practice of the breed, three types of lactation were detected: Type 1, a short lactation initiated in autumn; Type 2, a short lactation initiated in spring, following the Type 1 lactation; Type 3, a long lactation initiated in autumn. The Wood model (W) and a bi-exponential function (CB) were applied to fit milk yield data of individual lactations. Milk yield of the whole lactation was estimated both by integrating the $\mathrm{W}$ and $\mathrm{CB}$ functions, and by using the Fleischmann official method. The W model, after the restriction of $b>0$, fitted the original data better than the CB model, particularly in late lactation. However, the CB model was more adequate for describing the initial sudden rapid increase of milk yield. Differences among the three methods for the estimate of total milk yield were very small, even though the CB model slightly overestimated late lactation. Among the three types of lactations, Type 2 had a much earlier peak, a higher peak yield and a lower persistency than the other two types. The ewe's age at lambing influenced only the total milk yield, which reached the maximum at about 4 years of age. (C) 1999 Elsevier Science B.V. All rights reserved.
\end{abstract}

Keywords: Massese sheep; Milk yield; Lactation curve; Mathematical model; Lactation type

\section{Introduction}

To study the lactation curve of dairy sheep, several papers dealt specifically with the application of Wood's model (W model) to various sheep breeds (Torres-Hernandez and Hohenboken, 1980; CappioBorlino et al., 1989; Sakul and Boylan, 1992; Groenewald et al., 1995, 1996; Portolano et al. (1996a). Cappio-Borlino et al. (1995), however, proposed a non-linear modification of Wood's equation (a biexponential function) for the lactation curve of Sarda ewes in order to make it fit better the rising phase of

\footnotetext{
*Corresponding author. Tel.: +39 55 3288263; fax: +39 55 321216; e-mail: franci@zoot.agr.unifi.it
}

lactation which is often not adequately described by the $b$ parameter of the $\mathrm{W}$ model because of the very early occurrence of peak yield. The bi-exponential function (CB model) has also been successfully applied to the lactation curve of Comisana, another Italian sheep breed (Portolano et al., 1996b).

The Massese is one of the most important Italian dairy sheep breeds, producing about 200-300 kg milk per lactation. The reproductive performance of this sheep breed is characterized by a partial aseasonality of oestrus which can occur at any time during the year, though lambings are more frequent in autumn and in spring. The mating season is therefore continuous and often the rams are left among the freshly lactating ewes. Generally, lactation starts in the late summer or 
in autumn and lasts until May-June, but it is frequently interrupted, after a few months, by a new pregnancy, and followed by a new, shorter lactation in the spring. Normally, Massese ewes have three lambings every 2 years, alternating two short lactations in the first year with one long lactation the following year.

The aim of the present paper was to compare the $\mathrm{W}$ and CB models in their application to the lactation of Massese ewes and to analyse the influence of lactation-type and age at lambing on the parameters of the milk production curve.

\section{Materials and methods}

The experiment was carried out on 52 lactations of 37 Massese ewes that were at least in their second lambing and that belonged to the same flock. The milk yield, the sum of the two daily milkings, was recorded weekly during the whole lactation. Early weaning of the lambs made it possible to hand-milk the ewes and to obtain the first milk yield before the 15th day from lambing. Lambing occurred in autumn (SeptemberNovember), after which ewes were again continuously exposed to rams for mating, according to the usual breeding system with Massese sheep. Fifteen ewes conceived and lambed again in March-April, following a dry period of about 1 month. Those fifteen animals, therefore, had two short lactations in the year; one was in autumn (Type 1), which lasted on average $136(\mathrm{sd}=19.5)$ days; the second, initiated in the following spring (Type 2), which lasted 93.7 $(\mathrm{SD}=9.3)$ days. The remaining 22 ewes of the flock had only one long lactation (Type 3), which lasted on average $204.8(\mathrm{SD}=51.6)$ days.

The incomplete gamma function Eq. (1) (Wood, 1967) and the bi-exponential function Eq. (2) (Cappio-Borlino et al., 1995) were applied to fit the milk yield data of individual lactations:

$$
\begin{gathered}
y=a * x^{b} * \mathrm{e}^{-c * x} \\
y=a * x^{(b * \exp (-c * x))}
\end{gathered}
$$

where $y$ is the milk yield at day $x$ from lambing, e is the base of natural logarithm, and $a, b$ and $c$ are the parameters which characterize the shape of the curve and which were estimated from a non-linear regres- sion analysis using the NLIN procedure of SAS (1996) with Marquardt methodology.

Peak yield, time of peak yield, and persistency were estimated for each lactation as indicated in the original reports (Wood, 1967; Cappio-Borlino et al., 1995). Specifically, for Eq. (1) peak yield $a *(b / c)^{b} * \mathrm{e}^{-b}$ occurs at time $b / c$, while $c^{-(b+1)}$ is a measure of persistency. In Eq. (2) the time at peak yield is calculated iteratively by $T m=\mathrm{e}^{(1 /(c * T m))}$ and relative yield is obtained by substituting $T m$ in the original function; the persistency is estimated as $1 /\left(b^{*} c\right)$.

Total milk production of individual lactations was calculated from lambing and again from the 31st day post-partum to the end of lactation integrating the $\mathrm{W}$ and CB models or using the Fleischmann method according to the following expression:

$$
Y=y_{1} * t_{1}+\Sigma\left(\left(y_{i}+y_{i+1}\right) / 2 *\left(t_{i+1}-t_{i}\right)\right)
$$

where $Y$ is total production; $y_{1}, y_{i}$ are yields at first or $i$ th test day $(i=1 \ldots, k-1) ; t_{1}, t_{i}$ are times (in days) from lambing or from the 30th day at first or $i$ th test day.

Preliminary processing with the $\mathrm{W}$ model revealed that in a substantial proportion of lactations (about $50 \%$ ), the $b$ coefficient was negative, as already noted by other researchers (Cappio-Borlino et al., 1995; Portolano et al., 1996b). This finding, which can be attributed to the limited adaptability of the model to lactations characterized by sudden rapid increase in milk yield post-partum, contradicts the biological meaning of the parameter, which is to describe the rising phase of the curve: as a result with a negative coefficient the model estimated peak yield as occurring before the onset of lactation. For this reason Wood's model was fitted to individual data by adding the restriction that the $b$ parameter could only be positive, and that peak yield could not occur before day 1 .

The fitness of the models was estimated by means of the residual standard deviation for each lactation. The residuals (observed minus predicted) of both models were regressed on time (days in milk) up to the fourth degree to identify any definite pattern that might emerge.

A comparison between the ability of the $\mathrm{W}$ and $\mathrm{CB}$ models to estimate the characteristic parameters for lactation (time of peak yield and peak yield), and of W, $\mathrm{CB}$ and the Fleischmann method to estimate total yield was carried out using ANOVA, which considered the 
effects of method and individual lactation. Each lactation-type was also analysed individually since the factor-type of lactation influenced the shape of the lactation curve, as explained below.

Analysis of covariance was carried out on the peak time, peak yield, persistency and total milk yield estimated by the two models and the Fleischmann method using the model:

$$
y_{i k}=a+t_{i}+b * x_{i k}+c * x_{i k}^{2}+e_{i k}
$$

where $y$ is the observation of individual lactation; $a$ is the intercept; $t$ is the fixed effect of the lactation type $(i=1, . ., 3) ; x$ is the age of the ewe at lambing (from 738 to 3303 days) tested up to the second degree; $b$ and $c$ are linear and quadratic regressions coefficients, respectively, of yield on age; and $e$ is the residual error. The continuous effect of ewe age was preferred to the discrete effect of lactation number because it produced a smaller residual variance. Statistical analysis was performed using the GLM procedure of SAS (1996).

\section{Results and discussion}

\subsection{Comparison between models}

The $W$ function exhibited a lower residual standard deviation of milk yield than the CB model (223 vs. $232 \mathrm{~g})$. A significant $(p<0.01)$ fourth degree polynomial trend in the plot of residuals $x$ days was found for both models, even though $R^{2}$ values of regression were always very low ( 0.013 for $\mathrm{W}$ and 0.028 for $\mathrm{CB}$ ). Generally there was an underestimation of the true values in the first month and in the middle of the lactation period, and an overprediction during late lactation, particularly with the CB model. A similar trend for errors $x$ days in lactation was found by Grossman and Koops (1988), Williams (1993) and Montaldo et al. (1997), using the $\mathrm{W}$ model, and by Cappio-Borlino et al. (1995) using the CB model. This result, however, indicates that with Massese ewes the $\mathrm{W}$ model fitted the yield data better than the $\mathrm{CB}$ model, particularly during late lactation. Moreover, the original $\mathrm{W}$ model (without restriction for the $b$ parameter) exhibited a still lower standard deviation of residuals $(216.1 \mathrm{~g})$ and no significant trend of residuals $x$ days.
Table 1

Comparison between the methods to estimate peak yield, time to peak yield and total milk yield in the three types of lactation

\begin{tabular}{llll}
\hline & \multicolumn{2}{l}{ Lactation type $^{\mathrm{d}}$} & Pooled \\
\cline { 2 - 3 } 1 & 2 & 3 \\
\hline
\end{tabular}

\begin{tabular}{lrrrr}
\hline Peak time (d) & & & & \\
W model & $15.3^{\mathrm{a}}$ & $3.4^{\mathrm{a}}$ & $9.4^{\mathrm{a}}$ & $9.3^{\mathrm{a}}$ \\
CB model & $24.1^{\mathrm{b}}$ & $9.2^{\mathrm{b}}$ & $19.4^{\mathrm{b}}$ & $17.8^{\mathrm{b}}$ \\
Residual standard & 7.31 & 2.79 & 6.72 & 6.08 \\
deviation & & & & \\
& & & & \\
Peak yield (g) & & & & \\
W model & 2063 & $2158^{\mathrm{a}}$ & 1767 & 1965 \\
CB model & 1937 & $2346^{\mathrm{b}}$ & 1770 & 1984 \\
Residual standard & 216.1 & 223.6 & 157.1 & 209.8 \\
deviation & & & & \\
& & & & \\
Total milk yield (kg) & & & & \\
W model & & & & \\
CB model & $169.1^{\mathrm{a}}$ & 144.6 & $218.2^{\mathrm{a}}$ & 182.8 \\
Fleischmann & $163.3^{\mathrm{b}}$ & 147.4 & $215.9^{\mathrm{b}}$ & $181.0^{\mathrm{a}}$ \\
Residual standard & $173.2^{\mathrm{c}}$ & 144.4 & $219.5^{\mathrm{a}}$ & $184.5^{\mathrm{b}}$ \\
deviation & 5.24 & 7.09 & 2.35 & 5.48 \\
& & & & \\
Conventional milk & & & & \\
yield (kg) & & & & \\
W model & & & & \\
CB model & $114.9^{\mathrm{a}}$ & 86.8 & 169.1 & $129.7^{\mathrm{a}}$ \\
$\begin{array}{l}\text { Fleischmann } \\
\text { Residual standard }\end{array}$ & $116.3^{\mathrm{b}}$ & 91.1 & 169.9 & $131.7^{\mathrm{b}}$ \\
deviation & 116.1 & 87.4 & 169.3 & 130.3 \\
\hline
\end{tabular}

a, b, c means within column having different letters differ $(p<0.05)$.

d $1=$ short, initiated in autumn; $2=$ short, initiated in spring, $3=$ long, initiated in autumn.

${ }^{\mathrm{e}}$ Calculated from the 31 st day.

A comparison of estimates obtained with the methods is shown in Table 1. The CB model estimated the time of peak yield to occur about 9 days later than the $\mathrm{W}$ model. This delay persisted at the same level with all three types of lactation. Peak yield estimates were similar with both methods even though for Type 2 lactation (short, in spring) the CB estimate was almost $10 \%$ higher than the Wood estimate. Portolano et al. (1996b) compared the ability of these models to estimate the lactation of Comisana sheep, and they likewise found that the $\mathrm{W}$ model forecasted peak yield as occurring a week earlier, and at a slightly lower level, than the CB model.

The pooled total milk yield was underestimated by the $\mathrm{CB}$ model, especially when compared with the 
estimates of the Fleischmann method, but this was evident only with Type 1 and Type 3 lactations. For yields after the 30th day the estimates of the three models were more similar, but the CB model still tended to overestimate with respect to the $\mathrm{W}$ model. Portolano et al. (1996b), on the other hand, on Comisana sheep, found that $\mathrm{W}$ and $\mathrm{CB}$ models basically gave the same results, though with both these methods estimates were lower than with the Fleischmann method, probably because with the last method the productive period was projected for 14 days beyond the last control date.

\subsection{Effect of age of ewe and lactation type}

The effects of the type of lactation and ewe age at lambing on peak time, peak yield and persistency are shown in Table 2 for the Wood and CB model. Generally, the rather low $R^{2}$ values, especially with the W model, indicate that there remained a important amount of residual variation, which is to be ascribed to individual lactation behaviour.
As regards the type of lactation, the rank of estimates was the same in both methods. Type 2 lactation (short, in spring) had a much earlier peak, a lower persistency and a higher peak yield than Types 1 and 3, although differences between Type 2 and Type 1 lactations were not significant in the $\mathrm{W}$ model. Types 1 and 3 were more similar, though they differed statistically in peak yield with $\mathrm{W}$, and in time of peak yield with $\mathrm{CB}$ model. It should be noted that these findings were not affected by the duration of lactation, as was obtained by a separate analysis on only those lactations that started in autumn (Types 1 and 3). A certain effect of the lambing season on the parameters of the lactation curve was also found on the Comisana breed (Portolano et al., 1996a, b). These researchers reported that winter-initiated lactations (JanuaryMarch) showed an earlier and higher peak yield and a lower persistency than autumn lactations, which are generally consistent with the findings of the present study.

Though estimated values with other sheep breeds in other studies may not be strictly comparable, it should

Table 2

Effect of lactation type and of age at lambing on lactation parameters estimated by the W model and the CB model

\begin{tabular}{|c|c|c|c|}
\hline & Peak time $(\mathrm{d})$ & Peak yield (g) & Persistency \\
\hline \multicolumn{4}{|l|}{ W model } \\
\hline \multicolumn{4}{|l|}{ Lactation type $^{\mathrm{d}}$} \\
\hline 1 & $15.4 \mathrm{a}$ & $2060 \mathrm{a}$ & $5.32 \mathrm{a}$ \\
\hline 2 & $2.9 \mathrm{~b}$ & $2166 \mathrm{a}$ & $4.93 \mathrm{~b}$ \\
\hline 3 & $9.6 \mathrm{a}$ & $1763 \mathrm{~b}$ & $5.35 \mathrm{a}$ \\
\hline \multicolumn{4}{|l|}{ Regression on ewe age, (d) } \\
\hline Linear & $0.003(\mathrm{NS})$ & $-0.05(\mathrm{NS})$ & $0.0001(\mathrm{NS})$ \\
\hline Quadratic & (NS) & (NS) & $(\mathrm{NS})$ \\
\hline Residual standard deviation & 9.95 & 414.9 & 0.56 \\
\hline$R^{2}$ & 0.22 & 0.17 & 0.11 \\
\hline \multicolumn{4}{|l|}{ CB model } \\
\hline \multicolumn{4}{|l|}{ Lactation type $^{\mathrm{d}}$} \\
\hline 1 & $24.1 \mathrm{a}$ & 1939 a & 97.9 a \\
\hline 2 & $9.2 \mathrm{c}$ & $2338 \mathrm{~b}$ & $54.7 \mathrm{~b}$ \\
\hline 3 & $19.4 \mathrm{~b}$ & $1774 \mathrm{a}$ & $126.6 \mathrm{a}$ \\
\hline \multicolumn{4}{|l|}{ Regression on age } \\
\hline Linear & 0.0001 (NS) & 0.05 (NS) & $-0.016(\mathrm{NS})$ \\
\hline Quadratic & $(\mathrm{NS})$ & (NS) & $(\mathrm{NS})$ \\
\hline Residual standard deviation & 6.35 & 339.8 & 55.34 \\
\hline$R^{2}$ & 0.48 & 0.36 & 0.28 \\
\hline
\end{tabular}

a, b, c; within column means with different letters differ $(p<0.05)$.

$\mathrm{d}_{1}=$ short, initiated in autumn; $2=$ short, initiated in spring, $3=$ long, initiated in autumn.

NS, Not significant $(p>0.1)$. 
Table 3

Effect of lactation type and age at lambing on milk yield estimated with the three methods

\begin{tabular}{|c|c|c|c|c|c|c|}
\hline & \multicolumn{3}{|c|}{ Total milk yield $(\mathrm{kg})$} & \multicolumn{3}{|c|}{ Conventional milk yield $(\mathrm{kg})^{\mathrm{c}}$} \\
\hline & W & $\mathrm{CB}$ & Fleischmann & W & $\mathrm{CB}$ & Fleischmann \\
\hline \multicolumn{7}{|l|}{ Lactation type $^{\mathrm{d}}$} \\
\hline 1 & $166.2^{\mathrm{a}}$ & $160.7^{\mathrm{a}}$ & $170.4^{\mathrm{a}}$ & $112.3^{\mathrm{a}}$ & $113.8^{\mathrm{a}}$ & $113.5^{\mathrm{a}}$ \\
\hline 2 & $145.0^{\mathrm{a}}$ & $147.6^{\mathrm{a}}$ & $144.7^{\mathrm{a}}$ & $87.2^{\mathrm{a}}$ & $91.5^{\mathrm{a}}$ & $87.8^{\mathrm{a}}$ \\
\hline 3 & $219.9^{\mathrm{b}}$ & $217.6^{\mathrm{b}}$ & $221.3^{\mathrm{b}}$ & $170.6^{\mathrm{b}}$ & $171.3^{\mathrm{b}}$ & $170.7^{\mathrm{b}}$ \\
\hline \multicolumn{7}{|l|}{ Regression on ewe age $\left(\mathrm{gd}^{-1}\right)$} \\
\hline Linear & 91.3 & 85.3 & 90.8 & 80.7 & 78.7 & 79.9 \\
\hline Quadratic $^{\mathrm{e}}$ & -0.03 & -0.028 & -0.03 & -0.027 & -0.026 & -0.027 \\
\hline Residual standard deviation & 44.18 & 45.5 & 44.9 & 39.28 & 41.23 & 39.34 \\
\hline$R^{2}$ & 0.46 & 0.41 & 0.45 & 0.54 & 0.50 & 0.54 \\
\hline
\end{tabular}

a, bithin column means with different letters differ $(p<0.05)$.

${ }^{\mathrm{c}}$ Calculated from the 31 st day.

${ }^{\mathrm{d}} 1=$ short, initiated in autumn; $2=$ short, initiated in spring, $3=$ long, initiated in autumn.

${ }^{\mathrm{e}}$ All coefficients are significant $(p<0.01)$.

be noted that the time of peak yield obtained here by the $\mathrm{W}$ model (average 9.3 days) was earlier than that reported for Comisana sheep (14.3 days) by Portolano et al. (1996a), for various crossbreeds (16.5 days) by Torres-Hernandez and Hohenboken (1980), for Merinos (3 weeks) by Groenewald et al. (1995), and for Sarda sheep (4.6 weeks) by Cappio-Borlino et al. (1989), and that generally actual peak yield is higher than the estimates for those sheep breeds. It therefore seems that the milk yield of Massese ewes exhibits a more sudden and rapid increase than that of other sheep breeds, and it may be for this reason that the $\mathrm{W}$ model does not fit this yield so well in the initial phase.

Ewe age did not affect the parameters in any definite trend. By contrast, Portolano et al. (1996a) found an increase in peak yield from the first to the third lambing, but no clear trend for time of peak yield. In the present study, the absence of first lactations may have reduced a possible influence of ewe age on the parameters considered.

Table 3 shows the overall yields for the three types of lactation with each model of estimation. A general correspondence among the models was confirmed: the rank of the three types of lactation was similar. Type 2 lactation was the least productive, even though it did not differ significantly from Type 1 . Type 3 lactation had the greatest yield, as expected. However, average daily yield (not tabulated for brevity) revealed that Type 2 lactation was the most intense, followed by Types 1 and 3, in that order (estimates of average daily yield obtained 30 days in advance with the $\mathrm{W}$ model were $1353 \pm 47 ; 1086 \pm 48$; and $963 \pm 40 \mathrm{gd}^{-1}$, respectively). Overall yield was always influenced by age of ewe at lambing, following a parabolic pattern that reached its maximum at about 1500 days. This definite trend, which partially conflicts with the results for peak yield, indicates considerable variability in the shape of the curves obtained for this sheep breed and calls for further investigation, perhaps on a larger sample.

\section{Acknowledgements}

The authors acknowledge financial support from Ministero Università e Ricerca Scientifica e Tecnologica (40\% and $60 \%$ fund)

\section{References}

Cappio-Borlino, A., Pulina, G., Rossi, G., 1995. A non-linear modification of Wood's equation fitted to lactation curves of Sardinian dairy ewes. Small Rum. Res. 18, 75-79.

Cappio-Borlino, A., Pulina, G., Cannas, A., Rossi, G., 1989. La curva di lattazione di pecore di razza Sarda adattata ad una funzione del tipo gamma (The theorical lactation curve of Sardinian ewes estimated by a gamma-type function). Zoot. Nutr. Anim. 15, 59-63.

Groenewald, P.C.N., Ferreira, A.V., van der Merwe, H.J., Slippers, S.C., 1995. A mathematical model for describing and predicting the lactation curve of Merino ewes. Anim. Sci. 61, 95-101. 
Groenewald, P.C.N., Ferreira, A.V., van der Merwe, H.J., Slippers, S.C., 1996. Application of Bayesian inference in the comparison of lactation curves of Merino ewes. Anim. Sci. 62, 63-69.

Grossman, M., Koops, W.J., 1988. Multiphasic analysis of lactation curves in dairy cattle. J. Dairy Sci. 71, 1598-1608.

Montaldo, H., Almanza, A., Juarez, A., 1997. Genetic group, age and season effects on lactation curve shape in Goats. Small Rum. Res. 24, 195-202.

Portolano, B., Spatafora, F., Bono, G., Margiotta, S., Todaro, M., Ortoleva, V., Leto G., 1996a. Application of the Wood model to lactation curves of Comisana sheep. Small Rum. Res. 24, 7-13.

Portolano, B., Todaro, M., Spatafora, F., Bono, G., Margiotta, S., Giaccone, P., Ortoleva, V., 1996b. Confronto fra due modelli della curva di lattazione in pecore da latte di razza Comisana (A comparison between two different mathematical models of the lactation curve in dairy ewes of Comisana breed). Zoot. Nutr. Anim. 22, 323-331.

Sakul, H., Boylan, W.J., 1992. Lactation curves for several U.S. sheep breeds. Anim. Prod. 54, 229-233.

SAS (1996) - SAS/STAT User's Guide. 6.11 Version. SAS Institute Inc., Cary, NC, USA.

Torres-Hernandez, G., Hohenboken, W.D., 1980. Biometric properties of lactation in ewes raising single or twin lambs. Anim. Prod. 30, 431-436.

Williams, J.C., 1993. An empirical model for the lactation curve of white British dairy goats. Anim. Prod. 57, 91-97.

Wood, P.D.P., 1967. Algebraic model of the lactation curve in cattle. Nature (London) 216, 164-165. 